\title{
Coping with Change: The Small Experiment as a Strategic Approach to Environmental Sustainability
}

\author{
KATHERINE N. IRVINE \\ School of Natural Resources and Environment \\ University of Michigan \\ 430 E. University, Ann Arbor, Michigan 48109-1115, USA
}

\section{STEPHEN KAPLAN*}

Departments of Psychology and Computer Science and Engineering

University of Michigan

525 E. University, Ann Arbor, Michigan 48109-1109, USA

ABSTRACT / The patterns of living, planning, and resource utilization as practiced in Western countries for decades are not sustainable; change of some sort is essential. But what changes are appropriate, and, perhaps more important, will people accept them? The small experiment framework provides a strategy for meeting the challenge of change. By encouraging participation, limiting the scale of initial change, and incorporating some aspects of the familiar, many of the difficulties that make change so problematic can be mitigated or even eliminated. An exploration, from a psychological perspective, of the characteristic difficulties surrounding potential change provides the context for a discussion of the components of the small experiment and an analysis of how these elements address these characteristic challenges. A comparison to adaptive management is drawn, and several concrete examples illustrate how the strategy has been used successfully to address a variety of environmental problems.
The adoption of more environmentally appropriate patterns of living necessarily involves changing the current way of doing things, at both a personal and societal level. It is far less clear, however, exactly how best to foster potentially beneficial changes. There are not only questions of what to change but, of equal importance, of what not to change, as some tempting innovations are fraught with hidden costs. In the recent past environmental organizations have often considered legislation, frequently at a national level, as the method of choice for achieving needed change. Laws are farreaching, often creating mandates on a large scale. Though understandably an attractive approach, experience has shown that legislating solutions to complex problems entails many risks; even the best intended legislation can have unanticipated costs so severe as to make the very problem addressed worse rather than better (Sieber 1981).

Questions have also been raised about the efficiency and effectiveness of working at large scales to promote and encourage change. Estava and Prakash (1994) note that the popular phrase "think globally, act locally" suggests that actions taken at the local level can make as much (if not more) of a difference when compared to larger scale action. In addition to praising local action, the authors argue for thinking locally rather than glo-

KEY WORDS: Sustainability; Participation; Experiment; Local scale; Adaptive management; Environmental problem solving

*Author to whom correspondence should be addressed. bally, pointing out that it is easier to "think wisely about what one knows well" (Estava and Prakash 1994, p. 162). Drawing on what one "knows well" may facilitate taking action toward the attainment of environmental sustainability.

If one takes seriously the concept of thinking locally, and acting locally, one must also take seriously the local human resources that are necessarily part of the solution to a problem. All too often the public is a neglected, or largely untapped, resource. Finding ways to utilize this resource might go a long way toward solving our environmental problems and achieving sustainability.

Before we begin our analysis, a note on terminology might be appropriate. One difficulty in discussing the need for change and the types of change necessary is the strong feelings some have about the terms sustainable and environment. Some argue that sustainability is an inadequate goal; given the damage done to so many of the world's ecosystems, mere sustainability is not enough (Hawken 1993, McDonough and Braungart 1998). There is certainly merit to this position; nonetheless current human practices are, as a whole, still far from sustainable (Meadows 2000). The goal of sustainability is in the long run not sufficient, but in the short term it is clearly a step that is necessary and by no means trivial. Thus, given the importance of incrementalism (Johnson 1978, 1985) and the motivating power of attainable subgoals and "small wins" (Weick 1984), we have chosen to use the term sustainability. At the same time, the approach we propose is equally appro- 
priate to the steps beyond sustainability, as framed by such farsighted visions as "the next industrial revolution" (McDonough and Braungart 1998), "natural capitalism" (Hawken and others 1999), and the "global green deal" (Hertsgaard 1998).

In this article we propose an approach for achieving environmental sustainability that makes public participation an essential and constructive part of the process. Based on the "small experiment" concept (De Young and Kaplan 1988, S. Kaplan 1990, R. Kaplan 1996), this approach provides a way to test ideas without the risk of making a far-reaching or radical departure from the status quo. As a way to structure the process of solving environmental problems, the small experiment concept can facilitate the creation, evaluation, and the ultimate acceptance of potential solutions. By relying heavily on public participation, such an approach fosters familiarity with and a sense of ownership of solutions developed, both of which can aid the adoption process. Public participation can also lead to explorations of possible change that can be both more extensive and more economical than would otherwise be possible. And finally, by calling on human talent and ingenuity, small experiments can provide not only efficient solutions but ones that are satisfying as well.

The article first addresses the issue of why attempts to change the status quo are sometimes difficult for people. We then describe the small experiment as a possible approach to change. This is followed by a comparison of the small experiment approach to the adaptive management concept. We end with specific examples to illustrate how the small experiment strategy has been used successfully to address a variety of environmental problems.

\section{The Challenges of Change: A Psychological Perspective}

Change suggests that something is going to be modified, to be made different from its current incarnation. People have an inclination to be threatened by change (Grabiner and Miller 1974, Kaplan 1991). The thought of changing jobs, visiting a new city, or implementing new technology is frequently viewed with some apprehension. This fear of change is especially acute during times when many changes are occurring at once (Grabiner and Miller 1974). What is it that makes change so difficult? Why is it that a species as mobile, creative, and adaptable as humans has such difficulty with change? More pragmatically, how can solutions to pressing environmental problems be reached given this all too pervasive inclination?

The first step in dealing with people's resistance to change is to face the challenge of finding the "right" change; that is, a change that has a good chance of producing the desired effect and of minimizing undesirable side effects. Then one can proceed in good conscience (and with better chance of success) to the second step, the challenge of getting the proposed change adopted.

\section{Finding the "Right" Change}

The process of identifying a change that will improve a situation or correct a problem would, from a psychological perspective, be considered an instance of problem solving. If an individual or group stops to ponder a problem, the solution is presumably not obvious, because if it were, it would no longer be a problem. Thus, not knowing what to do next is the characteristic state of mind that leads to problem solving. Not knowing what to do next is generally due to a deficiency in one of three areas: pertinent knowledge, a source of variation, or a means of evaluation (Posner 1973). Let us examine each in turn.

Solving problems typically requires knowledge. In the modern world experts are often counted on to have the knowledge essential for solving problems in their respective areas. Examining the sorts of knowledge experts possess is instructive. Experts are trained to know what to focus on, what factors to attend to. This may be cash flow or water table level or form, line, color and texture, depending on the particular expertise involved. They also, because of their vast experience, have a rich repertoire of possibilities, of what might be done in a given situation and of what the consequences of a given decision might be. These are significant areas of knowledge and are often essential in solving a problem. It is important to remember, however, that there are other realms of knowledge that can also be useful. In the planning and management process, for example, knowledge of local tradition, local history, and local circumstances can play a central role (Ostrom 1990). These sorts of knowledge tend not to be available from the individuals traditionally regarded as experts.

Not infrequently a problem may resist solution not because of a lack of knowledge but because a crucial kind of variation is missing. The variation that is needed, interestingly enough, is not in generating possible solutions, but in ways of looking at the problem that needs to be solved. Research on problem solving indicates that the most common difficulty when problem-solving fails is that the usual ways of looking at the problem have not worked (Posner 1973, Bardwell 1991). The way one thinks of a problem (or, more technically, the way one represents the problem) turns out to be the single most important determinant of 
whether the problem is solvable (Posner 1973). The remedy for this might appear to be obvious: simply change the way of looking at the problem. This, however, is easier said than done. Not surprisingly, the way one perceives a problem is typically experienced as the right and natural way to understand the problem. In fact, it often seems to be the only reasonable way one could think about it. Thus, although some alteration in the way the problem is conceptualized is often essential, such variation typically is not easily achieved.

The third hazard in negotiating the problem solving process is evaluation (Anderson 1975). There are two sorts of situations in which evaluation is essential. Sometimes, when an impasse is reached, a solution is found by relaxing constraints (e.g., time, budget, goals). One becomes willing to entertain solutions that do not meet all of one's criteria. A solution obtained in this fashion may, of course, be unworkable; therefore, it is essential that the proposed solution receive an appropriate evaluation. At the other end of the spectrum, it is sometimes possible to think of a large number of solutions (a not uncommon situation in the context of planning and management). The difficulty then is not one of coming up with a solution but of deciding which solution, from among many, to implement. Here, too, evaluation is essential. In both cases evaluation is exceedingly difficult due to the impossibility of predicting in advance how a proposed solution will work out.

\section{Facilitating Adoption}

Once one or more possible "right" changes have been identified, there is the challenge of getting the proposed change or changes adopted. The reason this is so challenging can be stated simply, humans are much more comfortable with the known than the unknown (Zajonc 1968, Tversky and Kahneman 1973, Kaplan 1992). Although this is seemingly an inconsequential statement, it provides an important observation about human nature. The "known," whether it is a particular environment, person, or issue, is something about which one has some understanding. Understanding and comprehension are critical for knowing what to do. Being familiar with something is a way to achieve this understanding, whether that "something" is the surrounding physical or social environment or a more abstract concern (e.g., sustainability, ecosystem management). It appears, therefore, that humans have good reason for preferring the familiar. (At the same time people are motivated to make modest exploratory forays from the stable base of the known. The approach we describe in the next major section takes advantage of this motivation).

To understand why the bias toward the familiar is so powerful, it is useful to think about a specific instance of change. Computer software (e.g., word processing, data management), which is constantly being upgraded, provides a pertinent example. While often useful, the modifications may create anxiety and perhaps some resistance to the change. Actions that with the current version were routine, took little effort, and provided support for accomplishing a goal (e.g., writing a report, organizing data), may suddenly take longer and require considerably more attention. There may be uncertainty as to whether one will be able to meet deadlines; one may also experience irritation at the prospect of the time needed to learn the new version.

Although perhaps a trivial example of the power of the familiar, this example illustrates the benefits familiarity brings. Being familiar with a physical place (e.g., a city, a park, a neighborhood), an issue (e.g., forest management, water policy), or a relationship (e.g., between selective harvesting and wildlife biodiversity) allows one to recognize where one is, make decisions, predict, and evaluate possible next steps of action (Craik 1943, Kaplan 1973). Familiarity, in essence, as the above example illustrates, helps a person function more effectively in the world. The ability to function in one's surroundings, in turn, leads to feeling competent in one's abilities. Feeling as though one is good at and able to accomplish what one is doing is a powerful motivational force for humans (White 1959, De Young 1996).

Being able to function effectively is not the only reason to maintain the status quo. If people are resistant to change that in the long run is likely to work out, one would expect them to be even more hesitant where there is uncertainty about the alternative outcome (MacCrimmon and Taylor 1976, Slovik 1987). This concern may well be realistic. Using a new, alternative approach does not guarantee that the goal of a more sustainable relationship with the natural environment will be met. The potential for unintended consequences does, unfortunately, exist (Sieber 1981). Coupled with these may be the fear that something valuable could be lost (e.g., an endangered species, a "way of life") in the process of attaining sustainability. Given the time and energy involved in learning a new way of doing things (whether it be managing forests or maintaining viable populations of endangered species), in the face of uncertain results the tendency to be skeptical of new approaches is hardly surprising. Even if one knows it may not be the best alternative, there is indeed a strong inclination to stick with the current way of doing things in the face of possible future surprises. 


\section{Small Experiments: A Possible Strategy}

Perhaps if the process of change were less confusing and less overwhelming the resistance to adopting environmentally appropriate patterns of living would be minimized. In working to overcome this resistance to change, it would be particularly helpful if an approach could be found that enhanced familiarity with possible new alternatives.

One way to lessen resistance and increase familiarity would be to introduce change in incremantal steps; small steps would maintain a certain level of the familiar while still allowing for exploration of alternatives. Taking small steps would also make it possible to keep track of what effect each step had, an essential component for evaluating what one has done and deciding what step to take next. Last, an approach that encourages participation would be useful. Participation helps build familiarity and ownership of the process and incorporates the local knowledge and local talent that all too often go to waste.

The above description may sound similar to a concept known as "muddling through" (or simply "muddling"). There is indeed a similarity both to this concept and to "adaptive management" (Holling 1978, Walters 1986). We discuss the former in this section because it provides pertinent background to the small experiment notion. The comparison to an adaptive management approach is discussed later in the article after the small experiment concept is presented more fully. "Muddling through" is a phrase introduced by Lindblom (1959) to reflect the incremental, even groping, character of decision-making in large organizations (e.g., bureaucracies). Lindblom suggests that decisionmaking is actually quite a slow process, characterized by taking modest steps forward rather than grand leaps of faith. Johnson $(1978,1985)$ subsequently applied this concept to environmental management. The small experiment concept is akin to muddling in that they both approach change through taking small, manageable steps. Because steps are small, both techniques avoid big, potentially damaging mistakes. The scale of implementation, however, differs; small experiments focus on change at the local level while most discussions of muddling center on change at a larger scale (e.g., a large organization or an entire country).

Both techniques address the human bias toward the familiar by tying proposed changes to results of past changes, but small experiments allow many solutions to be explored simultaneously. Traditional muddling, by contrast, tends to focus on instituting only one policy at a time. This may be due to another difference between the approaches, namely, the role of citizen participa- tion. In muddling, the decision-making and implementation process are typically carried out by experts. Citizen input, when it occurs, may be sought primarily at the beginning of the process, when advice is garnered from those most likely to be impacted by a policy, or near the end, when the possibility of change is minimal. With small experiments, special emphasis is placed on providing creative opportunities for citizen involvement, permitting far more person power for parallel experiments.

A frequent criticism of muddling is its inability to respond quickly. Here the possibility of many parallel explorations is a major advantage of small experiments. Trying out several alternatives at the same time makes it easier to incorporate modifications in response to changes in the environment or the process. The possibility of multiple alternatives being explored at once, however, requires some way to assess their effectiveness. The luxury of just "getting an intutive feel for how things worked out" is unlikely to be affordable or useful when many efforts are being implemented simultaneously. The small experiment concept, thus, has an explicit focus on evaluation.

\section{The Small Experiment Concept}

Undoubtedly many activities that would appropriately be called small experiments are already under way. One might argue they are going on all the time. Sometimes called pilot projects, small studies, field tests, or prototyping, they are often simply a local response to local problems-innovative programs that arise out of frustration with the status quo. If small experiments are indeed a way in which to try out new and different approaches to the way people-environment relationships are managed, how can we make these efforts more helpful to the present state of affairs? How, also, might small experiments be made a more common approach to change? Some insight into these issues can be gained by examining the components of the "ideal" small experiment.

Purpose or goal. Small experiments have a specific purpose. This could be in the form of a question to explore (e.g., what would happen if. ..), a particular value to maintain (e.g., small-town character), or goal (e.g., improved water quality). Identifying a purpose provides the motivation for exploring ways of changing how things have always been done. A purpose also focuses attention on the ultimate outcome rather than on any one specific solution. The process thus becomes an exploratory one; the proposed changes are a possible solution rather than the solution. It is often easier to try something new if one knows that if it does not work or brings unintended consequences, one has not 
made a long-term commitment to it. Viewing the process as exploratory also means that some method of evaluating it is required. Having an articulated purpose provides clarity about what would constitute success or failure and facilitates the evaluation of the experiment's effectiveness.

Information gathering and evaluation. Formal or informal tracking of what happens both during and after implementing an "exploration" is a vital component of a small experiment for two reasons. First, it allows for feedback to participants. This feedback lets people know how things are going in general (e.g., are population numbers of a certain endangered species increasing) and provides information to individuals active in the effort about how their particular contribution has helped. Second, information gathering provides fodder for the process of determining what worked and what did not work. Such evaluation helps assess what steps, if any, to take next as well as identifies findings that are appropriate to share with others.

Scale and scope. Experiments need not be large and all-encompassing to be useful. What makes an experiment small, however, will vary from one circumstance to the next. "Smallness," therefore, can have a variety of referents. It may refer to the scale of the experiment or the elaborateness of the measurement, or the size of the sample. Taking a local scale approach, for example, may help avoid many of the potential pitfalls often associated with larger scale projects, such as the lack of funds and potential for details to overwhelm the process. Smaller-scale approaches often result in greater participation, with the scope often being dictated and managed by the people who are actually engaged in the experiment rather than by external considerations (e.g., source of funding). Given the uncertainty associated with change and the eternal question of whether the experiment will have the hoped-for results, perhaps it is safer to err on the side of too small rather than too big. This way any possible negative effects can be more easily remedied with minimal impact on the community.

Communication and dissemination of results. Letting others know about a particular strategy taken and the results of the effort is also an important aspect of the small experiment approach to change. Communicating the findings of a small experiment to a larger audience (people not directly involved in the project as well as people who live elsewhere) is essential if others are to profit and learn from the efforts. The strategy undertaken becomes, via dissemination, an available alternative that others can try in their own setting. Sharing information is one way to expand the level of knowledge of different approaches to sustainability. Present- ing the information in concrete and vivid language with a suggestion that more information is available a little farther down the road can enhance familiarity (Kearney 1994).

\section{Meeting the Challenges of Change: \\ Small Experiments and Participation}

Small experiments can in principle be carried out without the benefit of participation. It is our contention, however, that there are often considerable benefits to involving local citizens in the process. In this section we consider three interrelated issues concerning local participation. First we examine the way such participation can facilitate finding a promising solution. Then we turn to the issue of how it can aid adoption once such a solution is identified. But these benefits are for naught if local citizens are unwilling to participate. Thus, we conclude this section with a discussion of the basis for believing that participation will be experienced as a positively valued activity.

The impact of participation on finding the "right" change. The kind of knowledge that experts have is usually well represented in efforts to solve environmental problems. Other realms of knowledge, however, are often overlooked. These include the history and idiosyncrasies of the setting, the special resources that might be available, and what has been tried in the past. These kinds of knowledge are commonly held by local people.

A vivid example of the different ways of looking at the same issue comes from the Green Revolution. Clarkson (1970) describes a prototypic confrontation between an agricultural expert and an indigenous farmer of a less-developed country. Based on maps and theory, the expert suggests that a certain crop be grown in a certain field. The farmer refuses, referring to ghosts traditionally associated with the field. Although this may seem to be a straightforward conflict between reason and superstition, Clarkson (a geographer) points out that the local is likely to be in possession of long-term, detailed information about the productivity of that particular field-despite the information on the generalized map and despite the local's failure to describe this information in a way understandable to the expert. Thus, when local people are central to the problem-solving process a wider array of knowledge is available. Participation in the planning and carrying out of small experiments on the part of locals reduces the danger of neglecting information that may be vital to finding a solution to a problem.

The solution of difficult problems often depends on new and different ways of looking at the problem. This in turn requires diversity in how a problem is conceptualized. Incorporating local people into the process 
also addresses this need for diversity. People from the local community who are participating in the process are unlikely to have the same backgrounds, training, and perspectives the experts possess. Thus, they are likely to bring a variety of perspectives to the process. And, to the extent that citizens come from different backgrounds and have different work identities, they are likely to differ not only from experts but from each other as well, another useful source of diversity.

Evaluating a potential solution prior to widespread implementation is another facet of the problem solving process that can be aided through participation. It is often difficult to adequately evaluate proposed solutions without actually trying them out. In fact, in many situations there is no substitute for trying out an innovation on a small scale first. Peters and Waterman (1982) describe how this approach to evaluation has become institutionalized in some of the country's most highly regarded companies (e.g., IBM, 3M). Local participation provides more people power for trying things out on a small scale. When a sufficiently large group of people is interested, it becomes possible to test several alternative solutions at the same time. In this way the problem-solving process can be moved along at a more rapid and informed pace and the implementation of sweeping changes without the benefit of prior small scale evaluation can be avoided.

The impact of participation on adoption. People are often resistant and even disturbed by proposed change. One way to view this phenomenon is in terms of a lack of clarity. It is important to distinguish a lack of clarity from uncertainty. One can know a great deal about something and still face uncertainly (e.g., a surgeon facing surgery where the probability of a successful outcome is 0.6 ). People routinely make decisions where the outcome is uncertain. Unclarity, by contrast, entails not understanding the pertinent issues, not knowing what is important in the situation, and not knowing how to evaluate what is going on. Thus, not surprisingly, unclarity often inclines people to leave the situation or to avoid thinking about it (Kaplan 1978, 1991). Considerable evidence suggests that people react with discomfort and avoidance in the face of things they are unclear about (Bruner and Postman 1949, Maslow and Diaz-Guerrero 1971, Fortune 1976). Because potential change is a likely source of unclarity, their negative reaction is hardly surprising.

There are three key factors that reduce unclarity, namely, familiarity, understanding, and concreteness (S. Kaplan 1991, R. Kaplan and others 1998). Any activity that facilitates these three factors should reduce people's almost reflexive resistance to proposed changes. The small experiment is an ideal vehicle for achieving this. By giving people the opportunity to try something out, their familiarity is, by definition, increased. The proposal becomes more concrete as they implement a small-scale version of it in the real world. It becomes more understandable as they participate in carrying it out and observe its workings.

Some might worry that those participating in a small experiment will come to favor the proposed change independent of its merits. There are two reasons why this is unlikely to be the case. First, if the experiment is going badly the participants are not likely to have the confidence and enthusiasm necessary to convince others of its value. Second, persuading others is far more difficult when the results of the experiment are not favorable. The problem of adoption lies in the human tendency to resist change even when there is good reason to believe that it is needed and beneficial. A small experiment is a procedure that differentially favors the acceptance of workable proposals.

On the face of it, it might seem that the beneficial increase in clarity will only be experienced by those who have been directly engaged in a small experiment. If this were the case, it would be an important drawback, as the individuals who have participated are likely to constitute only a small fraction of the total population impacted. But a small experiment readily becomes a case study, or, more informally, a story about what other people did. Such shared experiences of having been involved in a small experiment have shown themselves to be a powerful source of information that makes it easier for people to take appropriate action themselves (Monroe and Kaplan 1988). Stories of this kind are more likely to be effective when people hear several of them rather than a single instance. This is not surprising because multiple examples are necessary to build a concept one can be comfortable with and confident of (Hebb 1949, Posner 1973, Rosch 1977). Fortunately small experiments are generally inexpensive, so that the launching of several in parallel may well be feasible. Further, such multiple experiments provide a sounder basis for action as well as a more effective means of building the understanding that facilitates adoption.

Will people actually get involved? These benefits of participation are, of course, contingent on a sufficient number of individuals being willing to participate. Though this might seem to be a serious limitation of the approach, there are, in fact, quite a few reasons for believing that people find such opportunities both attractive and satisfying.

Despite a strong desire for settings that foster understanding, humans, at the same time, have a natural inclination toward exploring and learning. Opportuni- 
ties for exploration have, in fact, been shown to be highly preferred (Kaplan and Kaplan 1989). The small experiment provides an opportunity for meeting these two potentially conflicting needs. In small doses, and in settings that are relatively familiar, exploring new approaches can be quite engaging and rewarding. Exploration is, after all, a process of expanding one's knowledge of the world. Small experiments allow discovery to occur while involving small enough increments of change to permit a feeling of familiarity and understanding to be preserved.

Second, because there are often fewer people and resources available for small-scale projects, involvement tends to be active rather than passive. Thus a small experiment might involve developing and testing different ways to reduce runoff as opposed to the more common citizen role of voting on a plan that was developed by an outside expert. The relative scarcity of resources and people in an "understaffed" context has been shown to increase the level of participation as well (Gump and Barker 1964). Fortunately, people tend to respond positively to opportunities to "do something" (Kaplan and Kaplan 1982), so the kinds of opportunities provided by small-scale projects draw on human motivations and inclinations (e.g., to learn, to be involved) that may be difficult to express under other circumstances.

As the name implies, a small experiment is something that takes place at a modest scale. There are many advantages of such an arrangement. Overall familiarity is maintained; mistakes, should they occur, are less costly. Participants understand what they can do and how their actions contribute to the process as a whole. Having this kind of an understanding of a situation has many advantages. It helps overcome the all-too-prevalent belief that individuals cannot make a difference, makes involvement enjoyable, and frequently leads to a sense of ownership and confidence in the process. An important by-product of participation is the fact that people find it satisfying (De Young 1985-86, 1996). In further support of this observation, Wandersman (1979a) found that in contrast to the those who did not participate, individuals in the participation condition "felt significantly more creative, responsible, helpful, and significantly less alienated and anonymous" (Wandersman 1979b, p. 480).

Concerning the meaning of "small" and "experiment". The expression "small experiment" refers to a way of learning from experience. It is an expression of the belief that there are many ways in which an experiment, a trying out of something, can be made less expensive and more manageable. It is an expression of the belief that an experiment need not be the intimidating task that it so often turns out to be. Given the many contexts in which the small experiment concept can be applied, it is impossible to define the "small" aspect of a small experiment with any exactness. In essence, it refers to any modification from the usual approach that reduces the cost, the effort, the duration, or the number of people affected relative to the usual way of doing things. Thus, the word small in small experiment plays a similar role to the word appropriate in appropriate technology; it is a reaction to the tendency of technology to get out of hand, to foster ever more elaborate and expensive solutions (Schumacher 1973).

There are two key consequences of such downsizing. First, the reality of current practice is that innovations in programs, policies, arrangements, and solutions are often put into effect on a large scale without the benefit of trying them first (Schumacher 1973, Peters and Waterman 1982). Untold harm has been done by apparently good ideas that not merely failed the test of time but did so on an unconscionably large scale. Thus, the focus on smallness is, to no small degree, an expression of frustration with current approaches.

A second benefit of taking smaller scale action concerns the notion of "experiment." The very idea of research has become so intimidating that it is not currently considered by individuals who are ideally positioned to learn from something that is about to happen anyway. There are so many new programs tried, so many opportunities to learn from experience that would be far more informative if they were thought of as experiments. Not as official, traditional, experiments, but as approximations, as modest efforts, as ways of preserving essential components of research (i.e., purpose, evaluation, communication) without bringing with them the expensive baggage. The alternative to runaway technology in the realm of trying things out needs a name, a philosophy, and a legitimacy. It is our hope and intention to contribute to the small but growing literature that attempts to address these needs. (It must be acknowledged that what one learns by experimenting at a smaller scale does not guarantee that it will behave similarly at a larger scale. But it is nonetheless vastly safer than not testing it at all.)

\section{Small Experiments and Adaptive Management- A Comparison}

Not surprisingly, the idea of employing a more experimental approach to guiding environmental decision-making is not without precedent. In particular, the adaptive management approach has received considerable attention for its utilization of this concept (Holling 1978, Walters 1986, Walters and Holling 1990, Johnson 1999a). It is useful to examine this approach both for its 
similarities and differences with respect to small experiments and for how it has fared in applied contexts.

Grounded in industrial operation theory (Everett and Ebert 1986), adaptive management was first applied to natural resource management in the $1970 \mathrm{~s}$ (Holling 1978). Central to the concept is the issue of uncertainty (e.g., about the resource, about the effect of management efforts). Unlike conventional management practices, which, for example, often attempt to make precise predictions and presume certainty, adaptive management accepts as given the reality of incomplete knowledge. It thus focuses on building opportunities to learn into the design and implementation of policies (Holling 1978, Walters 1986, Walters and Holling 1990). In this way, adaptive management emphasizes learning by doing (Walters and Holling 1990), treating management actions and policies as hypotheses, designing and implementing them so as to generate "critical information about the resource being managed” (Johnson 1999a, p. 1).

The approach typically includes several steps (Holling 1978, Lessard 1998, Lee, 1999, Johnson, 1999b). The assessment phase seeks to identify specific goals for the natural resource being managed (e.g., desired future condition of an aquatic ecosystem). These emerge from a collection of current knowledge about the resource with input from various stakeholders. The second phase identifies and assesses the significance of gaps in knowledge and generates alternative management actions. The actual implementation of management actions is treated as an experiment. Information is collected about the resource, impacts are monitored, and management actions are evaluated as to whether they are meeting management goals for the resource. The final step includes utilizing findings to revise policy as necessary.

It is instructional to look at where adaptive management and the small experiment concepts overlap and where they diverge. Both approaches attempt to bring a more scientific approach to the solution of practical problems. The emphasis on goal identification provides both concepts with a benchmark against which to determine whether efforts are addressing identified needs. Information collected during the process of implementation provides the basis for this continuous evaluation in both adaptive management and small experiments.

Both approaches identify the importance of sharing information and findings. The audience and intent, however, differ. Adaptive management focuses primarily on communicating findings to those immediately engaged in the process, with the intention of informing the implementation of management actions and poli- cies. Small experiments emphasize dissemination of information to a wider audience. In addition to those involved in the project, it also targets individuals in the vicinity but not directly involved with the project at hand, as well as individuals further away geographically, working on similar or different projects altogether. In essence, although both approaches create a feedback loop so that a current activity can inform future decision-making, the small experiments concept extends the dissemination beyond the immediate project at hand.

A second, and perhaps more significant difference is that of participation. Both approaches highlight the importance of participation, but the extent of involvement and who specifically is involved differ. In adaptive management participation occurs primarily during the goal identification phase, when relevant stakeholders are gathered to pool existing data about the resources and identify goals for the resource. Stakeholders are often identified by the managing organization (e.g., Forest Service) and usually consist of individuals with relevant expertise and knowledge (e.g., biologists; Pinkerton 1999, Shindler and Cheek 1999). There is less involvement at later stages of adaptive management and few opportunities for the average citizen. The small experiment expressly relies on participation throughout the process by experts as well as nonexperts. In fact, the distinction between experts and nonexperts is purposefully deemphasized in the small experiment concept, viewing the resource user (e.g., individuals using resource for fishing, walking) as an important source of creativity and of valuable local information.

A third difference is the scale of implementation. Much of the current literature discusses the application of adaptive management to the management of ecosystems (Lessard 1998, Gunderson 1999). Ecosystems, or eco-regions, typically cross boundaries (e.g., political, ecosystem type, ownership), presenting biological, economic, and social complexity on a large scale. Thus, adaptive management has tended to operate at and be perceived as a tool for larger scale management efforts. The small experiment concept suggests the value of applying an experimental approach to small-scale efforts as well (e.g., neighborhood water use campaign).

In light of the above discussion about the small experiment and adaptive management concepts, it may be useful to focus on what can be learned about and, perhaps more important, applied to efforts to create environmentally appropriate patterns of management and living. Adaptive management has been described as a tool for organizational decision-making, particularly for resource managers who are responsible for developing and implementing strategies and policies 
for natural areas (Johnson 1999b). The implementation and use of the adaptive management concept have, however, met with limited success (McLain and Lee 1996, Walters 1997, Gunderson 1999, Lee 1999). Describing the concept as "scientifically sound" yet "socially challenged," Johnson (1999a) identifies a need for greater participation from nonexperts. Drawing from the conceptualization of small experiments, a role for nonexperts should exist beyond merely providing additional information about the resource; such participants can also contribute new perspectives and approaches (Gunderson 1999). Participation by a broader array of stakeholders also has the added advantage of gaining greater acceptance for identified goals. Even though the involvement might require a change in the approach taken, the ultimate goal may be reached rather than stymied by public indifference or outright opposition.

Adaptive management puts emphasis on a systematic identification and collection of environmental data, and the use of technology for the development of multiple management strategies (e.g., computer modeling). This focus can make the process costly and slow (Walters and others 1993, Lee 1999). The small experiment concept takes a more informal, organic approach to information collection and solution generation. This could lead to missed information. Yet both concepts have their advantages, and in many situations the two approaches can be complimentary. There are, however, situations where speed, diversity of input, and acceptability to the public are sufficiently important that the small experiment approach might be preferable.

In general, adaptive management and small experiments appear to share considerable common ground. Both allow for the implementation of potentially risky strategies precisely because they are treated as experiments to be monitored and evaluated before adoption. At the same time, the adaptive management approach might benefit from adopting the broader concept of participation that is so central to the small experiment approach.

\section{Can Modest Projects Make a Difference?}

Is it realistic to think that such small-scale efforts can accomplish anything of substance in pursuit of the challenging goal of sustainability? A number of examples indicate not only that this is possible but that it is an approach rich in potential. Examples are drawn from different cultures, include national and international projects, and cut across several environmental issues. Innovative efforts undertaken in Davis, Califor- nia; the Amish community; Curitiba, Brazil; a small town in Wisconsin; and Ann Arbor, Michigan, demonstrate both the usefulness and the flexibility of the small experiment concept.

\section{Energy Efficient Buildings-Davis, CA}

The first example comes from attempts to reduce energy consumption. In the mid-1970s, in response to a national goal of energy conservation and conversion to renewable resources, Davis, California, developed a local-level solution based on local needs, constraints, and resources rather than relying on national legislation to solve the problem. The city designed its own building code around local climate conditions in hopes of increasing energy efficiency of new buildings. The idea arose out of research done at the University of California, Davis campus and was shaped by the comments and criticisms of many different segments of the community, such as environmental groups, energy groups, consumer advocates, builders, and developers. Evaluation was done primarily by those opposing the code to see if it really worked. One builder found that the inside temperature of unoccupied buildings, built under the new code, was $20^{\circ} \mathrm{F}$ cooler than the outside temperature on hot summer days, thus reducing the need for air conditioning and therefore energy use (Brunner 1980). City leaders in Davis have received numerous requests for information about their local energy policies. Builders now accept the new code as efficient and cost-effective, and the code has been adopted in nearby counties (Brunner 1980). The city of Davis provides a nice example of decisions and policies that were devised, explored, and implemented at the local level, in contrast to legislation passed at the national level, which would not have involved as many local groups and might not have adequately addressed local issues.

\section{Farming Technology Usage-Amish Culture}

In the context of environmentally sustainable patterns of behavior, decisions need to be made both about new practices intended to increase sustainability and about proposed innovations that may turn out to reduce sustainability and thus should be modified or rejected. If sustainability is a serious goal, then it is a consideration with respect to any innovation, not merely those intended to have an effect on the environment. The next example illustrates the use of the small experiment concept to purposefully evaluate, and ultimately reject, a new technological innovation.

The Amish maintain a lifestyle that in many respects is remarkably sustainable. Their practice is to examine innovation for consequences that may be quite far re- 
moved from the purposes that made the innovation attractive in the first place. The scale of these "experiments" remains small; the church units within Amish communities are inherently small and often only a few families "try out" the new technology (Huntington personal communication). The effects of an innovationa tractor, for example-are watched with keen interest and observations are communicated throughout the community both formally (e.g., at specific membership meetings) and informally (e.g., conversations with community members). Decisions about innovations are made against a backdrop of stability and community stemming from common, identifiable values shared by all in the community. The Amish wish to maintain their separateness from the "English," to maintain equal status among all members of their own community, and to maintain strong, healthy, families and communities (Huntington 1994). Thus, the Amish will question embracing the use of tractors, despite the increase in productivity a tractor could bring to their farming, because observation and communication would indicate that the use could ultimately upset the balance within the community and the separateness of the community from the larger society.

\section{Public Transportation and Waste Management- Curitiba, Brazil}

Curitiba, Brazil, provides an inspiring example of an attempt both to preserve key values and to make improvements with respect to both sustainability and the quality of life. Throughout efforts to modernize the city, the use of high-tech (and expensive) practices, believed to be essential to a modern city, was questioned; well-thought-out alternatives were explored, evaluated, and if determined to be appropriate, implemented. A particularly striking example was the decision to emphasize public transportation rather than individual car use, and to implement this decision using buses rather than a subway system. The city achieved remarkably high utilization levels through the use of such elements as dedicated bus lanes, subway-like terminals, and a public-private partnership for operating the buses. Interestingly, another factor favoring the choice of a bus system was the fact that the city was already familiar with the operation and management of buses. Thus, the thorny issue of how to provide transportation routes for the city's citizens was accomplished at a fraction of the cost of a subway system, drew on existing skills and knowledge, and had minimal impact on the environment. This is only one of the many experiments occurring at the same time in this fastdeveloping city. Each is targeted to a specific problem and places emphasis on appropriate technology, in achieving an environmentally and humanly satisfactory solution. As a result, the city has kept its pollution and crime rates lower and its educational level higher than is often the case with rapidly developing cities (Rabinovitch and Leitman 1996).

Curitiba has also created a waste management system that does not center around mechanized trashseparation plants-a recommended necessity for cities generating more than 1,000 tons of solid waste a day (Rabinovitch and Leitman 1996). The city has instead implemented labor-intensive programs that encourage citizen participation. Through both a separation program, in which citizens voluntarily separate their waste, and a purchase program, which allows families from neighborhoods difficult to service to exchange bags of trash for bus tokens, food, and school notebooks, Curitiba has managed to clean up the city, reduce waste going to landfills, provide employment, and conserve resources (Rabinovitch and Leitman 1996). Despite many important differences, Curitiba perhaps shows a parallel to the Amish example in their ability to say "no" to conventional wisdom and to the use of expensive high technology.

\section{Recycling-Wisconsin}

The last two examples focus on efforts made by individuals not normally viewed as agents of change. The first is of a Wisconsin woman nearing retirement who started a recycling company in 1978 (Sinclair and others 1990), well before recycling was a household word, let alone a household behavior. Her goal-to reduce the amount of waste destined for the landfill-was an outgrowth of her well-water being polluted due to leakage from a nearby landfill, and her realization that landfills were not the only solution to dealing with solid waste. As of 1987 the company had recycled 1,000 tons of refuse, saving the county $\$ 19,000$ in dumping fees (Sinclair and others 1990). The idea of recycling was initially greeted with skepticism. However, according to the company's owner, this attitude has changed dramatically; people now bring items that are washed, flattened, and ready for recycling. Thus, in this case, an individual brought change to the traditional practice of sending all household solid waste to a landfill.

\section{Water Quality and Lawn Care-Ann Arbor, Ml}

The issue of water quality provides the venue for the final example. Officials responsible for watershed protection are increasingly concerned about the impact of lawn chemicals on the quality of groundwater. Due to the vast commercial investment in providing such lawn care and the cultural attachment to the traditional 


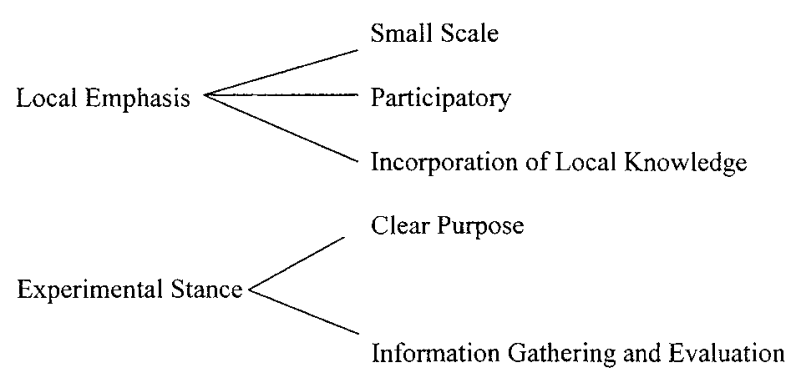

Information Sharing

Figure 1. Small experiment themes.

lawn, addressing this problem is likely to be challenging. Perhaps children, who will ultimately pay the price for chemically green lawns, could be an appropriate vehicle for this message. An experiment at the scale of a local neighborhood provides an indication of how such an approach might work (Romaker 1995). A group of preschool students in Ann Arbor, Michigan, went door-to-door, explaining to their neighbors the implications of and their concerns with lawn chemicals. They asked individuals to sign a pledge agreeing to stop applying chemical lawn sprays. About $50 \%$ of the people with whom the children talked agreed to sign the pledge and received a "safe lawn" sign to place on the lawn to let others know of their commitment (Romaker 1995). Results of the children's efforts were written up in the local newspaper.

There are many problems implicit in moving from current practice to sustainability. The small experiment approach is presented as a framework for addressing the challenges of building a sustainable relationship between people and the natural environment. The approach can be thought of in terms of three themes: local emphasis, experimental stance, and information sharing (see Figure 1). The examples cited above all incorporate, to a greater or lesser degree, the three themes and provide insight into how they can be utilized.

Local emphasis can occur in a variety of ways. For instance, in the examples cited above, note the different scales at which efforts to change the status quo can be successful - city, community, small town, and neighborhood. In each instance, an issue (e.g., water quality, energy conservation, community) was addressed in an exploratory manner, at a scale smaller than the issue might usually be treated, with an emphasis on learning about consequences before extensive resources were committed and great disruption occurred. Participation by individual citizens, a key concept in the small experiment approach, goes beyond providing input on other people's decisions. Citizens can have a role in shaping policy, as in the case of Davis's energy policy, or in the Amish's decisions regarding use of technology. Citizens can actively participate in alleviating problems, as in Curitiba, or could develop a program to reduce the use of toxic chemicals on lawns, as in Ann Arbor. In each case, local knowledge is utilized in meaningful ways.

The examples also illustrate the numerous ways in which the purpose or goal, central to the experimental stance, can be formulated. For example, the Amish emphasize maintenance of community-oriented values, the city of Curitiba is working toward solutions of civic and environmental problems in the context of citizen participation, whereas in the other examples conservation of resources, such as water quality or energy, is the focus. How information is gathered and evaluated also varies, from the informal networks between neighbors, as with the Amish and the preschool children, to more formal venues such as the testing done by opponents of the Davis housing code system.

Information sharing was also present in all cases. Findings and results were communicated and disseminated via word-of-mouth and informal networks of colleagues (as between Davis city officials and other cities) and more formal channels, such as biannual meetings of the community (as done in the Amish setting) or newspaper articles.

It is hopeful to see that many noteworthy efforts have been and are being made to address the issue of environmental sustainability. At the same time, the efforts cited, though promising, could benefit from a more vivid awareness of the importance of the local emphasis and experimental stance themes, which might have increased their effectiveness. Additionally, the scope of information sharing was limited. The dissemination that did occur was due as much to chance factors as to conscious intent. If the small experiment is to realize its full potential, more systematic means of making this rich source of information available need to be employed. By encouraging participation in the exploration of alternative solutions, and by making participants aware of the usefulness of the various features of a small experiment, many worthy goals would be accomplished. Knowledge about what works would grow rapidly. Vast quantities of human talent and ingenuity now underutilized or wasted would be engaged in stimulating and worthwhile effort. The incorporation of local knowledge and skills would increase the number and diversity of alternatives worthy of consideration. Additionally, familiarity with new alternatives and openness to making appropriate changes is likely to grow as the level of participation increases. Finally, there is reason 
to believe that both life satisfaction and commitment to environmental concerns would benefit as well.

\section{Acknowledgments}

We would like to thank Trudy Huntington for her help in exploring the connection between the small experiment concept and the Amish approach to living. We are also indebted to Jodi Asarch, Gordon Bradley, Rachel Kaplan, Steve Lippman, Elizabeth McCance, Bill Nichols, and Ali Phillips for their input. The feedback from the three reviewers, Richard E. Saunier, D. Scott Slocombe, and Robert Staib, was most helpful and greatly appreciated.

\section{Literature Cited}

Anderson, B. F. 1975. Cognitive Psychology: The Study of Knowing, Learning, and Thinking. Academic Press, New York, 402 pp.

Bardwell, L. 1991. "Problem-framing: A perspective on environmental problem solving." Environmental Management 15(5):503-612.

Bruner, J. S., and L. Postman. 1949. On the perception of incongruity: A paradigm. Journal of Personality 18:206-233.

Brunner, R. D. 1980. Decentralized energy policies. Public Policy 28(1):71-91.

Clarkson, J. D. 1970. Ecology and spatial analysis. Annals of the Association of American Geographers 60(4):700.

Craik, K. J. W. 1943. The nature of explanation. Cambridge University Press, Cambridge, 123 pp.

De Young, R. 1985-86. Encouraging environmentally appropriate behavior: The role of intrinsic motivation. Journal of Environmental Systems 15(4):281-291.

De Young, R. 1996. Some psychological aspects of reduced consumption behavior: The role of intrinsic satisfaction and competence motivation. Environment and Behavior 28(3): $358-409$.

De Young, R., and S. Kaplan. 1988. On averting the tragedy of the commons. Environmental Management 12(3):273-283.

Estava G., and M. S. Prakash. 1994. From global to local thinking. Ecologist 24(5):162-163.

Everett, E. A., Jr., and R. J. Ebert. 1986. Production and operations management: Concepts, models, and behavior. Prentice-Hall, Englewood Cliffs, NJ, 860 pp.

Fortune. 1976. The stock market is "efficient." Fortune 93(6): 147.

Grabiner, J. V., and P. D. Miller. 1974. Effects of the Scopes trial. Science 185:832.

Gump, P. V., and R. G. Barker. 1964. Big school, small school: High school size and student behavior. Stanford University Press, California, 250 pp.

Gunderson, L. 1999. Resilience, flexibility and adaptive management-Antidotes for spurious certitude? Conservation Ecology 3(1):7.
Hawken, P. 1993. The ecology of commerce: A declaration of sustainability. HarperCollins Publishers, New York, 250 pp.

Hawken, P., A. Lovins, and L. H. Lovins. 1999. Natural capitalism: Creating the next industrial revolution. Little, Brown and Company, Boston, 396 pp.

Hebb, D. O. 1949. The organization of behavior: A neuropsychological theory. John Wiley and Sons, New York, 333 pp.

Hertsgaard, M. 1998. Earth odyssey: Around the world in search of our environmental future. Broadway Books, New York, 372 pp.

Holling, C. S. (ed.). 1978. Adaptive environmental assessment and management. John Wiley and Sons, New York, 377 pp.

Huntington, G. E. 1994. Persistence and change in Amish education. Pages 77-95 in D. B. Kraybill and M. A. Olshan, eds., The Amish struggle with modernity. University Press of England, London, 304 pp.

Johnson, B. L. 1999a. Introduction to the special feature: adaptive management-scientifically sound, socially challenged? Conservation Ecology 3(1):10.

Johnson, B. L. 1999b. The role of adaptive management as an operational approach for resource management agencies. Conservation Ecology 3(2):8.

Johnson, W. 1978. Muddling toward frugality. Shambhala, Boulder, CO, 252 pp.

Johnson, W. 1985. The future is not what it used to be: Returning to traditional values in an age of scarcity. Dodd, Mead and Company, New York, 246 pp.

Kaplan, R. 1996. The small experiment: Achieving more with less. Pages 170-174 in J. L. Naser and B. B. Brown, eds., Public and private places. Environmental Design Research Association, Edmond, OK.

Kaplan, R., and S. Kaplan. 1982. Cognition and environment: Functioning in an uncertain world. Praeger, New York. Republished by Ulrich's Books, Ann Arbor, MI. 1989, 287 pp.

Kaplan, R., and S. Kaplan. 1989. The experience of nature: A psychological perspective. Cambridge University Press, Cambridge. Republished by Ulrich's Books, Ann Arbor, MI, 1996, 340 pp.

Kaplan, R., S. Kaplan, and R. Ryan. 1998. With people in mind: Design and management of everyday nature. Island Press, Washington, DC, 225 pp.

Kaplan, S. 1973. Cognitive maps in perception and thought. Pages 63-78 in R. M. Downs and D. Stea, eds., Image and environment: Cognitive mapping and spatial behavior. Aldine Publishing Company, Chicago, 439 pp.

Kaplan, S. 1978. Attention and fascination: The search for cognitive clarity. Pages 84-90 in S. Kaplan and R. Kaplan, eds., Humanscape: Environments for people. Duxbury Press, Mass. Republished by Ulrich's Books, Ann Arbor, MI, 1982, 480 pp.

Kaplan, S. 1990. Being needed, adaptive muddling and human-environment relationships. Pages 19-25 in R. I. Selby, K. H. Anthony, J. Choi, and B. Orland, eds., Coming of age, proceedings of Environmental Design Research Association's twenty-first conference. Environmental Design Research Association, Edmond, OK.

Kaplan, S. 1991. Beyond rationality: Clarity-based decision- 
making. Pages 171-190 in T. Garling and G. Evans, eds., Environment, cognition and action: An integrated approach. Oxford University Press, New York, 357 pp.

Kaplan, S. 1992. Environmental preference in a knowledgeseeking, knowledge-using organism. Pages 581-598 in J. H. Barkow, L. Cosmides, and J. Tooby, eds., The adapted mind: Evolutionary psychology and the generation of culture. Oxford University Press, New York, 666 pp.

Kearney, A. 1994. Understanding global change: A cognitive perspective on communicating through stories. Climatic Change 27:419-441.

Lee, K. N. 1999. Appraising adaptive management. Conservation Ecology 3(2):3.

Lessard, G. 1998. An adaptive approach to planning and decision-making. Landscape and Urban Planning 40(1-3):8187.

Lindblom, C. E. 1959. The science of muddling through. Public Administration Review 19:79-99.

MacCrimmon, K. R., and R. N. Taylor. 1976. Decision making and problem solving. Pages 1379-1454 in M. D. Dunnette, ed., Handbook of industrial and organizational psychology. Rand McNally College Publishing Company, Chicago, 1740 pp.

Maclain, R. J., and R. G. Lee. 1996. Adaptive management: Promises and pitfalls. Environmental Management 20:437-448.

Maslow, A. H., and R. Diaz-Guerrero. 1971. Adolescence and juvenile delinquency in two different cultures. Pages 369378 in A. H. Maslow, ed., The farther reaches of human nature. Viking Press, New York, 423 pp.

McDonough, W., and M. Braungart. 1998. The next industrial revolution. Atlantic Monthly 282(4):82-92.

Meadows, D. 2000. Trying to measure nations' sustainability. Timeline E-mail Edition May/June.

Monroe, M., and S. Kaplan. 1988. When words speak louder than actions. Journal of Environmental Education 19(3):38-41.

Ostrom, E. 1990. Governing the commons: The evolution of institutions for collective action. Cambridge University Press, Cambridge, 280 pp.

Peters, T. J., and R. H. Waterman. 1982. In search of excellence: Lessons from America's best-run companies. Harper and Row, New York, 360 pp.

Pinkerton, E. 1999. Factors in overcoming barriers to implementing co-management in British Columbia salmon fisheries. Conservation Ecology 3(2):2.

Posner, M. 1973. Cognition: An introduction. Scott Foresman, Glenview, IL, 208 pp.
Rabinovitch, J., and J. Leitman. 1996. Urban Planning in Curitiba. Scientific American 274(3):46-53.

Romaker, R. L. 30 April, 1995. Preschool kids making a difference in environment. Ann Arbor News, p. C5.

Rosch, E. 1978. Principles of categorization. Pages 27-48 in E. Rosch and B. B. Lloyd, eds., Cognition and categorization. L. Erlbaum, Hillsdale, NJ, 328 pp.

Schumacher, E. F. 1973. Small is beautiful: Economics as if people mattered. Blond and Bridges Ltd., London, 305 pp.

Shindler, B., and K. A. Cheek. 1999. Integrating citizens in adaptive management: A prepositional analysis. Conservation Ecology 3(1):9.

Sieber, S. D. 1981. Fatal remedies: The ironies of social intervention. Plenum Press, New York, 234 pp.

Sinclair, T., R. Hoops, and S. Wittman, eds. 1990. Earthwatching III. University of Wisconsin Institute for Environmental Studies and Sea Grant Institute, Madison.

Slovik, P. 1987. Perception of risk. Science 236:280-285.

Tversky, A., and D. Kahneman. 1973. Availability: A heuristic for judging frequency and probability. Cognitive Psychology 5:207.

Walters, C. J. 1986. Adaptive management of renewable resources. MacMillan Publishing Company, New York, 374 pp.

Walters, C. J. 1997. Challenges in adaptive management of riparian and coastal ecosystems. Conservation Ecology 1(2):1.

Walters, C. J., and C. S. Holling. 1990. Large-scale management experiments and learning by doing. Ecology 71:2060 2068.

Walters, C. J., R. D. Goruk, and D. Radford. 1993. Rivers Inlet Sockey salmon: An experiment in adaptive management. North American Journal of Fisheries Management 13:253-62.

Wandersman, A. 1979a. User participation: A study of types of participation effects, mediators, and individual differences. Environment and Behavior 11(2):185-208.

Wandersman, A. 1979b. User participation in planning environments: A conceptual framework. Environment and Behavior 11(4):465-482.

Weick, K. E. 1984. Small wins: Redefining the scale of social problems. American Psychologist 39(1):40-49.

White, R. W. 1959. Motivation reconsidered: The concept of competence. Psychological Review 6:313-324.

Zajonc, R. B. 1968. Attitudinal effects of mere exposure. Journal of Personality and Social Psychology 9:1-27. 